development and appropriate remedial education as necessary. In families of NF-1 patients, at-risk children who have not developed cafe-au-lait spots or Lisch nodules by 5 years of age are virtually certain to have escaped inheritance of the dominant gene. (Huson SM et al. Von Reckinghausen neurofibromatosis. $A$ clinical and population study in southeast wales. Brain Dec 1988; $111: 1355-1381)$.

COMMENT. This article represents a major study and addition to the literature on neurofibromatosis type 1. Items of interest to the pediatric neurologist include the association of macrocephaly, mental retardation, and epilepsy. Hypsarrythmia occurred more frequently than expected with NF-1 ( 2 cases) and this association has been noted previously (Riccardi VM, Eichner JE (1986) Neurofibromatosis: Phenotype, Natural History, and Pathogenesis. Baltimore, Johns Hopkins University Press). For correspondence, Dr. Huson's present address: Kennedy Galton Centre for Clinical Genetics, Northwick Park Hospital, Watford Road, Harrow, Middlesex HA1 3UJ, UK.

\title{
DRUGS IN TREATMENT OF DEVELOPMENTAL DYSLEXIA
}

An acute 2 day trial of methylphenidate (10 $\mathrm{mg}$ ) and of meclizine (12.5 $\mathrm{mg})$ and a 6 month crossover placebo-controlled chronic trial of meclizine $(12.5 \mathrm{mg})$ in children with developmental dyslexia are reported from the University of Calgary, Alberta, Canada. Oral reading fluency, coordination, and motor accuracy improved on methylphenidate, and clinical improvements of eye fixation and tracking were found with meclizine, in acute trials. Three of 6 children showing benefit from acute doses of meclizine also showed significant improvements in eye fixation stability after 3 months chronic administration of the drug $(12.5 \mathrm{mg} \mathrm{BD})$, but measures of reading skills including comprehension, phonetic analysis, structural analysis, achievement, and oral and silent reading rates, were not benefitted. (Fagan $\mathrm{JE}$ et al. The failure of antimotion sickness medication to improve reading in developmental dyslexia: results of a randomized trial. J Dev Behav Pediatr Dec 1988; 9 :359-367).

COMMENT. Levinson has proposed a theory of cerebellarvestibular dysfunction as the etiology of dyslexia and has claimed that treatment with antimotion sickness medications may result in improvement in reading in 778 of cases of dyslexia. The present study fails to confirm these results and suggests that antimotion sickness drug treatment of dyslexia is unjustified. The relationship between fixation error and impaired reading is not completely understood, however. Geiger and Lettvin have found that dyslexics have poor foveal vision, but when the target is moved into the peripheral visual field, their ability to identify letters is better than control nondyslexic subjects. Imperfect oculomotor control in the dyslexic may be accompanied by abnormalities of visual processing and cognitive difficulties that impede the acquisition of reading skills. Further work on this aspect of dyslexia seems justified. 